Bangladesh J. Zool. 44(2): 275-280, 2016

- Scientific note

ISSN: 0304-9027 (print)

2408-8455 (online)

\title{
HAEMATOLOGICAL PROFILE OF LABEO CALBASU (HAMILTON): A COMMON INDIGENOUS FISH SPECIES OF BANGLADESH
}

\author{
Tahmina Khanam*, Gulshan Ara Latifa ${ }^{1}$ and Shibananda Shil ${ }^{2}$ \\ Department of Biotechnology and Genetic Engineering, \\ University of Development Alternative, Dhaka, Bangladesh
}

The purpose of present studies was to lead the haematological parameter of kalibaus fish (Labeo calbasu) of Bangladesh. This study was conducted in the Bargen Laboratory the Department of Zoology, University of Dhaka as well as in the people's pathological lab, a private diagonist laboratory at Dhaka city from July 2008 to April 2009 for a period of 9 months in natural condition to establish a standared haematological profile. Eight type of blood cells in periphereal condition of this speices could be used as stress indicator to determine the physiological state of fish population in natural condition and their general health performance for normal growth. Studies were carried out to identify the different haematological parameter under electronic microscope. The monthly changes were recorded according to weight of fish. The average celluar counts of Labeo calbasu were erythrocytes $6.03 \times 10^{6} \mathrm{~mm}^{-3}$, leococytes $34.920 \times 10^{3} \mathrm{~mm}^{3}$ thrombocytes $10.21 \%$, large lymphocytes $55.49 \%$, small lymphocytes $24.77 \%$, Monocytes $4.74 \%$, Neutrophils $22.46 \%$, Eosinophils $5.13 \%$ basophils $3.76 \%$, haemoglobin $21.72 \%$ and erythrocytes sedimentation Rate $3.04 \mathrm{~g} 100 \mathrm{ml} / 1$. Most of this mentioned haematological parameters showed intra specific variation except eosinophil, basophils and ESR of Labeo calbasu

Fish is a great source of dietary protein typically low in fat which helps to grow and develop human body without distressing health risks. It is about $60 \%$ of animal protein supplies were fulfilling from fish resources in Bangladesh. The culture fishery contributes over $55 \%$ of inland fish production which covers only about $11 \%$ of the total inland water resources. Fisheries contribution to national GDP is $3.69 \%$ and to agricultural GDP is $23.12 \%$, but the scenario is needed to be changed to assure the protein demand. So, increasing fish production could be an immense solution to satisfy the rising protein demand with parallel to the

*Author for correspondence: tahmina31@yahoo.com> 1Department of Zoology, University of Dhaka, Dhaka-1000, Bangladesh. 2University Grants Commission of Bangladesh, Agargoan, Dhaka, Bangladesh.

(C) 2016 Zoological Society of Bangladesh DOI: 10.3329/bjz.v44i2.32767 
population growth. Lack of proper scientific management, unplanned housing, physio-chemical change, industrial and insecticidal pollution are responsible for decreasing the optimal fish production in Bangladesh.

The genus Labeo is an enigmatic group containing more than 100 species including Labeo calbasu which belongs to the family Cyprinidae; extremely widespread and has been recorded from major river systems in most of India, Bangladesh, Pakistan, Nepal, Myanmar and southern China but the common locality ranged to Bangladesh, Bengal and western provinces of India. Locally it is known as Calibaus. This species apparently spawns in shallow water during the wet season, and is also farmed in commercial hatcheries due to its low mortality, high nutrition value and taste as well. But optimal fish culture system requires know-how about the standard physiological conditions of the fish species. Since, the performance of a fish species is dependent upon the interaction between the inherited characteristics and the environment whereas, the changes of the environment are reflected in the physiological process including haematological parameters of that species. So, studies on blood constituents of fishes have assumed greater significance with the increasing emphasis on the pisciculture and changing water environment. According to Blaxhall and Daisly (6 edition), it is important to establish a range of normal values for each species for the purpose of health assessment. Even, haematological studies are now a days took a new dimension as it is now dealing with the influence of different stressors, diseases, environment and other factors in cultured condition. The blood of $L$. calbasu is a pale colored fluid and volume varies between $02 \%$ and- $08 \%$ of the body volume. One third to half of the total blood volume of fish consists of blood cells and rest of the fluid is plasma. The studies and observation of this species are made in order to establish a standard haematological profile for future use.

Gupta and Gupta in 1981 made a detailed study on the haematological parameters of Channa punctatus and show that the number of monocyte, lymphocyte, eosinophil, polymorph and basophil. Coagulation time was 25 - 50 sec.

The experiment was conducted in the laboratory of the Department of Zoology, University of Dhaka during July, 2008 to April, 2009.

For haematology, the fishes were collected every month during the experimental period from four different locations of Bangladesh. Based on length fishes were classified to four different groups including 25 to 28,29 to 32,33 to 36 and $37 \mathrm{~cm}$ and above. Similarly, based on weight fishes were classified to five different groups including 401 to 500,501 to 600,601 to 700,701 to 800 and $801 \mathrm{gm}$ and above. Each time more than twenty individual L. calbasu fishes 
were collected from the freshwater and initially screened for the experiment. All the diseased or contaminated or injured fishes were excluded from the experiment.

Live fish was put on a bed in a tray. A damp cloth was used to cover the fish head. Immediately after catching the fish, a small sample of whole blood was drawn from the caudal vein into dipotassium EDTA containing blood collection tube by the process as described by the following The tubes were transferred to the laboratory with maintaining proper temperature and transportation techniques. Finally, all the haematological parameters were determined. Jain The haematological parameters included RBCand WBC counting, ESR, PCV, haemoglobin and DLC. Red blood cell (RBC) counts and total leucocytes counts were carried out with a haemocytometer, haemoglobin concentration $(\mathrm{Hb})$ was measured by Sahlis method and packed cell volume (PCV) was determined by means of a haematocrit method.

Erythrocytes of $L$. calbasu were ellipsoidal in form, nucleus was clear and takes auricular purple stain with Giemsa. Cytoplasm was of lightly stained violet color. Leucocytes were two types- agranulocytes and granulocytes, thrombocytes, lymphocytes (large and small) and monocyotes were Agranulocytes. Neutrophils, eosinophils and basophils were Ggranulocytes. Thrombocytes constituted 52 to $58 \%$ of total leucocytes. They were oval with ellipsoid nucleus. Large lymphocytes were 3 to6\% of total leucocytes of varied shapes from circular to amoeboid. Small lymphocytes were constituted only $2-5 \%$ of total leucocytes globular in shape and its nucleus had variable forms. Neutrophils constituted $20-30 \%$ of total leucocytes. They were generally round in shape and large. Its nucleus had a variable form. Eosinophils were in only $3-6 \%$ of total leuvocytes. They were typically amoeboid with irregular shape nucleus. Basophils were rounded nucleus.

Platelets were absent in fish blood. Erythrocytes containing haemoglobin play a vital role in vertebrate respiration. The studies of erythrocytes in $L$. calbasu reveal a remarkable difference in their size and counts in different months in response to the physiological and environmental conditions in which they live. Monthly fluctuation of erythrocytes showed decreasing trend in dry season and after breeding period. According to length fluctuation rate decreased in the lower length group and increasing trend was observed in higher length group and smaller weight group showed lower erythrocyte counts. The total haematological parameters and monthly fluctuations are presented in the Table 1.

Similarly, $801 \mathrm{gm}$ to above sized group gave the highest pick about all the haematological parameters except ESR (Fig. 1). 
The present study showed that, the gradual increase of the all haematological parameters in all groups from April to December but, monocytes and ESR. Mamta and Trivedi\#(2016)\#reported that, heavy metal like chromium stress reduces the ESR level in Channa punctatus (Bloch). Our study can be

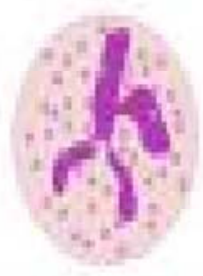

Neutrophil

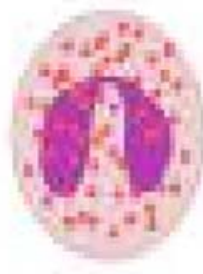

Cosinophil

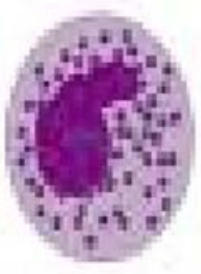

Basophil

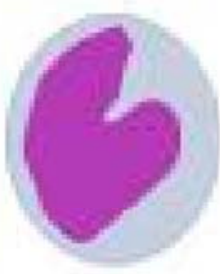

Monocyte

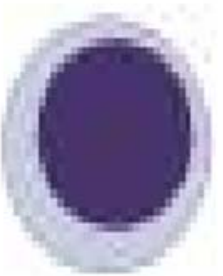

Lymphocyte

Photograph of white blood cells

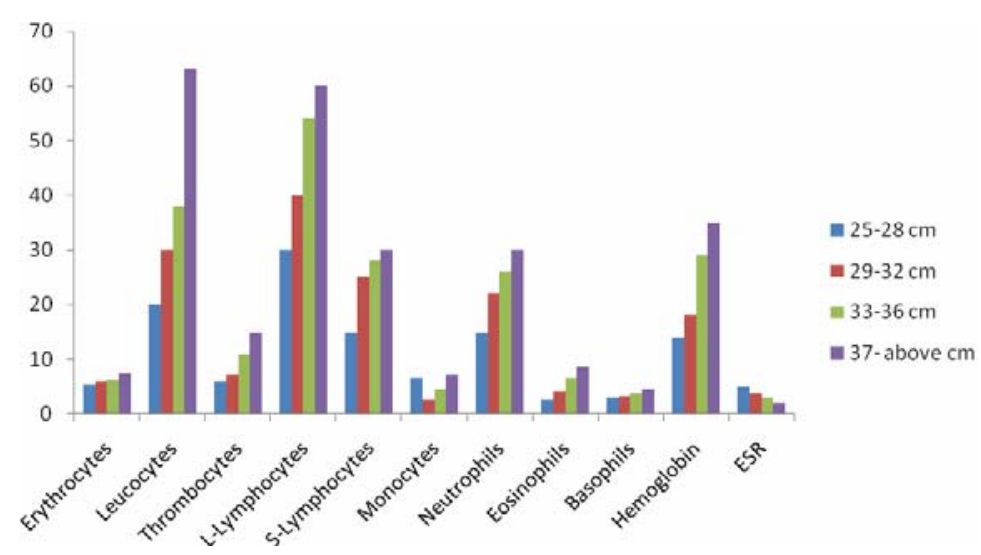

Fig. 1. Length wise erythrocytes, leucocytes, thrombocytes, L-lymphocytes, S-lymphocytes, monocytes, neutrophils, eosinophils, basophils, hemoglobin and ESR in the blood of L. calbasu.

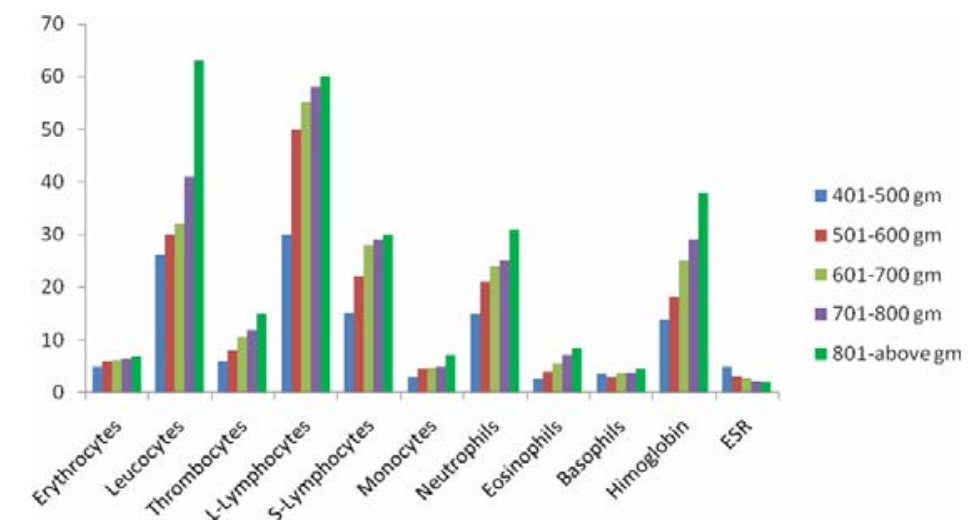

Fig. 2. Weight wise erythrocytes, leucocytes, thrombocytes, L-lymphocytes, S-lymphocytes, monocytes, neutrophils, eosinophils, basophils, hemoglobin and ESR in the blood of L. calbasu. 


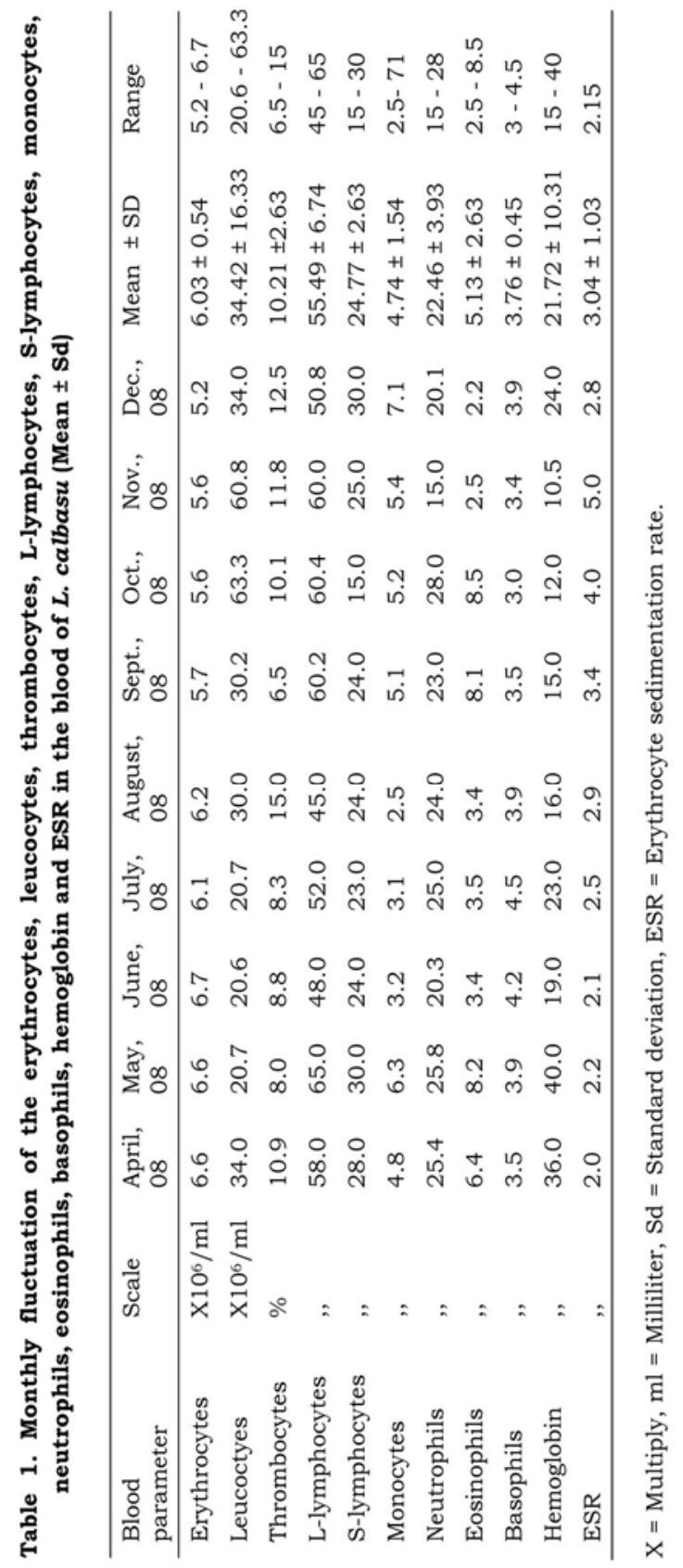


explained with these findings.The ESR of L. calbasu's ESR was highest in November when the heavy metal concentration is minimum due to rise of water and ESR level was minimum in April due to highest concentration of heavy metal in water. But all other parameters, decreased periodically.

It has been illustrated that the use of haematological variables as indicators can provide information on the physiological response of fish to a changing external environment. Increasing salinity up to a certain level of $L$. calbasu, thereby they bring about adaptive physiological changes in order to compensate, partially or completely. However, extreme stress can have alterations on haematology and internal physiology, and finally inability to adapt leads to metabolic depression, thereby affecting growth.

\section{LITERATURE CITED}

Blaxhall, P. C. and K. W. Daisley. 1973. Routine haematological methods for use with fish blood". Journal of Fish Biology 5(6): 771-781.

FAO National Aquaculture Sector Overview (NASO). Fao. org. N.p., 2016.

Gupta B.K. and Gupta R.B. 1981. Haematological observation on the Channa punctatus. Ind. J. Zool. 9(2): 51-55.

Hawkins and Mawdesley, Thomas 1981. Fish haematology bibliography A.J. Fish Biol. 4: 193-232

Hrubec, T.C. and Smith, S.A. 2000. Haematology of fish. In: Schalm's Veterinary Haematology. 5th edn Edited by Feldman, B.F. Zinkl, J.G. and Jain, N.C. Lippincott Williams \& Wilkins (USA) 34: $1120-1125$

Jain, N.C. 1986. In: Schalm's veterinary haematology, depression or hypo proliferative anaemia's, 4th edn, edited by Lea and Febiger (Philadelphia PA), 4: 655-75.

Labeo Calbasu - Orangefin Labeo (Cyprinus Calbasu, Labeo Reynauldi). Seriously Fish. N.p., 2016. Web. 24 July 2016.

Mamta, Pal and S. P. Trivedi 2016. Impact of chromium trioxide on haematological parameters of freshwater fish, Channa punctatus (Bloch). European Journal of Experimental Biology 6(2):40-42.

Water Pollution Control. 2016, A guide to the use of water quality management principle Published by E \& FN Spon, an imprint of Thomson Professional, 2-6 Boundary Row, London SE1 8HN, ISBN- 0419229108, 24 July 2016.

(Manuscript received on 20 August, 2016; revised on 06 November, 2016) 